NBER WORKING PAPER SERIES

\title{
CAPITAL ACCOUNT LIBERALIZATION, INSTITUTIONAL QUALITY AND ECONOMIC GROWTH: THEORY AND EVIDENCE
}

\author{
Michael W. Klein \\ Working Paper 11112 \\ http://www.nber.org/papers/w11112 \\ NATIONAL BUREAU OF ECONOMIC RESEARCH \\ 1050 Massachusetts Avenue \\ Cambridge, MA 02138 \\ February 2005
}

I thank Laura Alfaro, Steven Block, May Boggess, Linda Goldberg, Larry Marsh, Giovanni Olivei, Bent Sørensen, Linda Tesar, Joel Trachtman, David Weil, and seminar participants at Clark University, Dartmouth College, the Kennedy School, Notre Dame University, the Federal Reserve Bank of New York, and Tel Aviv University for helpful comments. I also thank Dennis Quinn for providing data. The views expressed herein are those of the author(s) and do not necessarily reflect the views of the National Bureau of Economic Research.

(C) 2005 by Michael W. Klein. All rights reserved. Short sections of text, not to exceed two paragraphs, may be quoted without explicit permission provided that full credit, including $\odot$ notice, is given to the source. 
Capital Account Liberalization, Institutional Quality and Economic Growth: Theory and Evidence Michael W. Klein

NBER Working Paper No. 11112

February 2005, Revised November 2005

JEL No. F32, F33, F36

\begin{abstract}
$\underline{\text { ABSTRACT }}$
This paper shows that the effect of capital account liberalization on growth depends upon the environment in which that policy occurs. A theoretical model demonstrates the possibility of an inverted-U shaped relationship between the responsiveness of growth to capital account liberalization and institutional quality. Three empirical specifications based on the model are estimated using a panel of 71 countries. Estimates of all three specifications support the hypothesis of a non-monotonic interaction between the responsiveness of growth to capital account liberalization and institutional quality, with about one-quarter of the countries, those with better (but not the best) institutions exhibiting a statistically significant and economically meaningful effect of capital account openness on economic growth.

Michael W. Klein

The Fletcher School of Law and Diplomacy

Tufts University

Medford, MA 02155

and NBER

michael.klein@tufts.edu
\end{abstract}




\section{$\underline{\text { 1. Introduction }}$}

The positive experience of industrial countries that opened up to international capital flows since the early 1980s, and the boom in emerging market economies during the first half of the 1990s, bolstered the argument that an open capital account promotes growth and development. But, in the wake of the economic and financial crises in emerging markets in the latter part of the 1990s, critics questioned the wisdom of this type of economic integration. These critics include well-respected mainstream economists who strongly favor free trade in goods and services, but maintain that trade in assets fundamentally differs from trade in "widgets." For example, in an influential article published in Foreign Affairs in 1998, Jagdish Bhagwati wrote "substantial gains [from capital account liberalization] have been asserted, not demonstrated ..." (p. 7). In a similar vein, Dani Rodrik (1999) warned "Openness to international capital flows can be especially dangerous if the appropriate controls, regulatory apparatus and macroeconomic frameworks are not in place.” (p. 30). By the end of the decade, a report by the International Monetary Fund (2000) stated that the Executive Board of that institution “...has emphasized the substantial benefits of capital account liberalization, but stressed the need to carefully manage and sequence liberalization in order to minimize risks." Reviewing this topic, Kenneth Rogoff, then the Chief Economist and Director of Research for the IMF, wrote in the December 2002 issue of the IMF's publication Finance and Development "These days, everyone agrees that a more eclectic approach to capital account liberalization is required." (p. 55).

A careful reading of the warnings advanced by Rodrik, the Executive Board of the IMF, and Rogoff, however, does not suggest that open capital accounts cannot have a 
salutary effect; rather, they argue that the environment in which capital account liberalization occurs is a potentially important determinant of its consequences. But the conditions under which capital account liberalization contributes to economic growth are not evident from previous published empirical research.

Earlier empirical literature offers conflicting results concerning the effect of capital account openness on growth. ${ }^{1}$ Quinn (1977), who includes an indicator of capital account openness in a standard growth regression, provides the first evidence that an open capital account promotes growth. Klein and Olivei (1999) show that an open capital account is associated with greater financial depth and, through this channel, it can promote growth. The results presented in Grilli and Milesi-Ferretti (1995), however, show no effect of an open capital account on growth. Rodrik (1998) demonstrates that capital account openness may only serve as a proxy for institutional quality and have no independent significant effect in a growth regression. Edwards (2001) and Arteta, Eichengreen, and Wyplosz (2003) investigate the effect of a linear interaction between the capital account liberalization indicator and income per capita in cross-country growth analysis, with the former finding a significant effect for higher income countries while the latter, using somewhat different estimation techniques, finding no significant effects.

The results presented in this paper help resolve the ambiguity of this earlier empirical work since the empirical specification used here nests specifications in previous research. This specification is based on a neoclassical growth model developed in Section 2 that focuses on the manner in which institutional quality affects the impact of

\footnotetext{
${ }^{1}$ See the survey by Edison, Klein, Ricci and Sløk (2004).
} 
capital account liberalization on growth. ${ }^{2}$ Institutional quality, in this model, affects the extent to which savings are protected from expropriation and it also affects the premium borrowers pay for funds from abroad. The effect of institutional quality on the steady state level of output differs when there is an open capital account as compared to when there is autarky. The responsiveness of growth to capital account liberalization reflects the relative values of these two steady states. Therefore, institutional quality affects this responsiveness and, in particular, a key result is that it may vary in a non-monotonic manner with institutional quality.

This model provides a theoretical foundation for the analysis of the effect of capital account liberalization on growth presented in Section 3. Consistent with this model, the results presented in this section provide evidence of an inverted - U shaped relationship between the effect of capital account liberalization on growth and institutional quality. About one-quarter of the 71 countries in the sample, those with better (but not the best) institutions exhibit a statistically significant and economically meaningful effect of capital account openness on economic growth. This result is robust to different specifications of the interaction between institutional quality and an indicator of capital account openness. Thus, the results presented in this paper offer conditional

\footnotetext{
${ }^{2}$ In its focus on the interaction between the capital account and institutional quality, this paper is related to other recent research. Castro, Clementi and MacDonald (2004) develop a model in which the positive effects of investor protection on growth are strongest for countries with more open capital accounts because access to international capital holds interest rates steady even as better institutions increase the demand for investment. They also present cross-country evidence consistent with this model. Along another dimension, Alfaro, Kalemli-Ozcan and Volosovych $(2003,2005)$ present crosscountry evidence that capital inflows are significantly and positively affected by institutional quality.
} 
support for a policy of capital account liberalization, with the quality of domestic institutions serving as an important determinant of whether integrating into the world capital market delivers on the promise of more rapid economic growth.

\section{Capital Account Liberalization, Institutional Quality, and Growth}

The model presented in this section illustrates how the effect of capital account liberalization on the growth rate of a small open economy depends upon the quality of its domestic institutions. Institutional quality in this model affects the extent to which domestic savings translate into investment as well as the premium demanded by foreigners when investing in the domestic economy. Section 2.1 presents a neoclassical growth model of a small open economy with two types of capital under the conditions of financial autarky whereby all capital is funded from domestic savings. An alternative version of this model for a small open economy, one that includes partial capital mobility (following Barro, Mankiw and Sala-i-Martin 1995) is presented in Section 2.2. Section 2.3 models capital account liberalization by drawing on the solutions for the autarkic and partial capital mobility cases. The model shows that, for reasonable functions relating institutional quality to expropriation and the risk premium, the responsiveness of growth to capital account liberalization, while positive, may first increase, and then decrease, with higher levels of institutional quality. As discussed in Section 3, the empirical results support this inverted U-shaped relationship between the responsiveness of growth to capital account liberalization and institutional quality. 


\subsection{Steady State Output and Growth under Financial Autarky}

The model used in this paper has two types of capital, $K$ and $H$. The distinction between these types of capital relates to whether they can serve as collateral when borrowing from abroad. ${ }^{3}$ Thus, under financial autarky, the situation studied in this subsection, there is little difference in the characteristics of $K$ and $H$ but, as discussed below, an important difference exists between these two types of capital when international borrowing and lending occurs.

The production function for this economy includes $K$ and $H$, as well as $L$, the number of workers, and $E$, the efficiency of labor, and is given by

$$
\text { [1] } \quad Y=K^{\alpha} H^{\beta}(E L)^{1-\alpha-\beta}
$$

where $Y$ is output, and both $\alpha$ and $\beta$ are between 0 and 1 . We study the model with the variables expressed in terms of effective units of labor, and define $y=Y / E L, k=K / E L$ and $h=H / E L$. Using these variables, the production function is

$$
\text { [2] } y=k^{\alpha} h^{\beta}
$$

The model attempts to capture the link between institutional quality and the responsiveness of growth to capital account liberalization through the effect of institutional quality on the return to savings. The parameter representing institutional quality in this model is $q(0<q \leq 1)$ with larger values of $q$ indicating better institutions. In this model, the quality of institutions affects the rate of expropriation of capital by

\footnotetext{
${ }^{3}$ Barro, Mankiw and Sala-i-Martin (1995) identify $H$ as human capital, a natural interpretation since expected future wages typically cannot serve as collateral. It is reasonable, however, to broaden the definition of $H$ to other types of capital as well. For example, differential collateral requirements exist for foreign direct investment and international portfolio investment, a point stressed by Froot and Stein (1991) in their model of the link between the real exchange rate and foreign direct investment.
} 
governmental or private actors who are not appropriately constrained by law, as captured by the function $x(q)$. This function represents the proportion of savings that contributes to physical investment, with $x^{\prime}(q)>0$ and $x(1)=1$. This function appears in the capital accumulation equations for both $K$ and $H$ under autarky, when both types of capital can only be accumulated through domestic savings, as shown in the two equations in [3], that express capital accumulation in terms of $k$ and $h$.

$$
\begin{aligned}
& \frac{\dot{k}}{k}=\frac{s_{K} \cdot x(q) \cdot y}{k}-(\delta+n+g) \\
& \frac{\dot{h}}{h}=\frac{s_{H} \cdot x(q) \cdot y}{h}-(\delta+n+g)
\end{aligned}
$$

In the two equations in [3], $\frac{\dot{L}}{L}=n, \frac{\dot{E}}{E}=g, s_{K}$ is the proportion of savings devoted to the formation of $K, s_{H}$ is the proportion of savings devoted to the formation of $H$, and $\delta$ is the rate of depreciation of both types of capital. ${ }^{4}$

The steady state value of output per effective unit of labor of this economy under financial autarky, $y_{A}^{*}$, is

$$
\text { [4] } \quad y_{A}^{*}=\left(\frac{s_{K}^{\alpha} s_{H}^{\beta} x(q)^{\alpha+\beta}}{(n+g+\delta)^{\alpha+\beta}}\right)^{1 /(1-\alpha-\beta)}
$$

\footnotetext{
${ }^{4}$ In addition to $q$ affecting the use of savings, the quality of institutions could also affect the savings rate. In this case, we could posit the relationships $s_{K}(q)$ and $s_{H}(q)$, where $s_{K}{ }^{\prime}(q)>0$ and $s_{H}{ }^{\prime}(q)>0$. This would not change the qualitative effects of institutional quality in this model since $\frac{d\left[s_{K}(q) x(q)\right]}{d q}>0, \frac{d\left[s_{H}(q) x(q)\right]}{d q}>0$. Also, it would be straightforward to allow for different $x(q)$ functions for the two types of capital.
} 
Naturally enough, steady state output per effective unit of labor in autarky is higher with a higher level of institutional quality (a higher value of $q$ ) because better institutions lead to a higher proportion of savings being used for productive investment.

Below we will compare the dynamic path of output per effective worker under autarky and under partial capital mobility. A Taylor-series expansion around the steady state yields the differential equation for output per effective unit of labor under autarky

[5] $\quad \frac{y}{y}=-(1-\alpha-\beta)(n+g+\delta)\left[\ln (y)-\ln \left(y_{A}^{*}\right)\right]$.

\subsection{Steady State Output and Growth with Partial Capital Mobility}

With no restrictions on its movement, and no cost of adjustment, capital would move instantaneously to capital-scarce countries and equalize rates of return across nations. A model with this feature would have no meaningful transition dynamics. The results of such a model are obviously at odds with experience. A more reasonable result is obtained if one assumes partial capital mobility, whereby there is perfect international capital mobility for some types of capital but not for others. Barro, Mankiw and Sala-iMartin (1995) formalize this concept by assuming that physical capital, $K$, can serve as collateral and, as such, can be fully funded by foreign borrowing while $H$ cannot serve as its own collateral. In an economy that is credit-constrained, $H$ can only be accumulated through domestic savings. ${ }^{5}$

\footnotetext{
${ }^{5} \mathrm{~A}$ country is credit-constrained if the overall value of its assets that can serve as collateral, $K$, is less than or equal to the value of its debt, $D$, where $D=(K+H)-A$, and $A$ is the overall value of assets of an economy. In the model below, we assume that the credit constraint is binding (else there would be no transition dynamics).
} 
When $K$ can serve as collateral in international asset trade, the amount of physical capital per effective worker, $k$, is determined by an equilibrium condition that sets the marginal return of capital equal to its marginal cost. The marginal return of capital is the marginal product of capital net of its rate of depreciation and net of expropriation. Institutional quality affects the rate of expropriation and, therefore, the premium that must be paid to foreign lenders. This premium is assumed to be a negative function of institutional quality, $v(q)$, where $v^{\prime}(q)<0$ and $v(1)=\varepsilon$ where $\varepsilon$ is a small premium associated with international lending, even in the presence of no expropriation. The arbitrage condition for $k$ is, therefore,

$$
\text { [6] } \frac{\partial y}{\partial k}-\delta-v(q)=r_{W}
$$

where $r_{W}$ is the (exogenous) world interest rate. This equilibrium condition holds regardless of whether or not a country is capital constrained. An analogous equilibrium condition does not hold for $h$ in a credit-constrained economy; rather, in this case, the $\frac{\dot{h}}{h}$ equation given in [3] determines its path of accumulation.

The steady state levels of $h$ and $y$ in a credit-constrained economy are obtained by using the equilibrium condition for $k$ (Equation [6]) in the steady state, and the steady state value of $h$ consistent with the equation of motion for that variable in Equation [3]. The steady state level of output per effective unit of labor under this assumption of partial capital mobility, $y_{G}^{*}$, is

[7] $y_{G}^{*}=\left(\frac{\alpha^{\alpha} \cdot s_{H}^{\beta} \cdot x(q)^{\beta}}{(n+g+\delta)^{\beta} \cdot\left(r_{W}+\delta+v(q)\right)^{\alpha}}\right)^{1 /(1-\alpha-\beta)}$. 
As in the case under autarky, steady state output per effective unit of labor is higher with a higher level of institutional quality when there is partial capital mobility since $x^{\prime}(q)>0$ and $v^{\prime}(q)<0$. A distinction between the effect of institutional quality on the steady state levels of output under partial capital mobility and under autarky arises because $k$ is financed through foreign lending in the former case while it is financed through domestic savings in the latter, and institutional quality has different effects on these two sources of financing investment.

The differential equation that describes the dynamic path of an open economy is

$$
\frac{\dot{y}}{y}=-\lambda\left[\ln (y)-\ln \left(y_{G}^{*}\right)\right]
$$

where $\lambda=\frac{1-\alpha-\beta}{1-\alpha}(n+g+\delta)$. Comparing this result to the differential equation for an autarkic economy in equation [5], we see that the rate of convergence is more rapid for a country with partial capital mobility than for a country that operates under financial autarky (a point noted in Barro, Mankiw and Sala-i-Martin 1995).

\subsection{Solutions and Empirical Specification}

The empirical specification of the effects of capital account liberalization on growth, and the demonstration of how this effect depends upon institutional quality, draws on the solutions to the differential equations for an economy under financial autarky, [5], and for an economy with open capital markets, [8]. ${ }^{6}$ These solutions,

\footnotetext{
${ }^{6}$ This use of the model to generate an empirical specification is similar to Mankiw, Romer and Weil (1992) who develop an estimating equation from a standard Solow growth model.
} 


$$
\begin{aligned}
& \text { Autarky: } \ln (y(t))=\left(\ln (y(0))-\ln \left(y_{A}^{*}\right)\right) \exp (-\lambda(1-\alpha) t)+\ln \left(y_{A}^{*}\right) \\
& \text { Open }: \ln (y(t))=\left(\ln (y(0))-\ln \left(y_{G}^{*}\right)\right) \exp (-\lambda t)+\ln \left(y_{G}^{*}\right)
\end{aligned} .
$$

allow us to determine the average rate of growth of output per effective unit of labor over the period 0 to $T, \frac{1}{T} \ln \left(\frac{y(T)}{y(0)}\right)$, when an economy has a liberalization of its capital account at time $F$ (where $0 \leq F \leq T$ ). The indicator of capital account openness in this model, $\kappa$, represents the proportion of years between year 0 and year $T$ that a country has an open capital account, and is defined as

$$
\kappa=\frac{T-F}{T}
$$

Thus, $0 \leq \kappa \leq 1$, with $\kappa=0$ for a country that that is closed throughout the period and $\kappa=$ 1 for a country that is open throughout the period. ${ }^{7}$ Assuming continuity in the path of output between the time before and the time after the liberalization of the capital account, the solution for the average rate of growth of output per effective unit of labor for an economy that spends the first $(1-\kappa) T$ years with a closed capital account and the remaining $\kappa T$ years with an open capital account is

$$
\begin{aligned}
\frac{1}{T} \ln \left(\frac{y(T)}{y(0)}\right) & =-\frac{1}{T}\left\{\left(1-e^{-\lambda T(1-\alpha(1-\kappa))}\right)\right\} \ln (y(0))+\frac{1}{T}\left[\left(1-e^{-(1-\alpha) \lambda T(1-\kappa)}\right) e^{-\lambda T \kappa} \ln \left(y_{A}^{*}\right)+\left(1-e^{-\lambda T \kappa}\right) \ln \left(y_{G}^{*}\right)\right] \\
& =-\frac{1}{T} C \ln (y(0))+\frac{1}{T} S
\end{aligned}
$$

\footnotetext{
${ }^{7}$ It is worth noting that $\kappa$, the proportion of years that a country has an open capital account, directly corresponds to the standard indicator of capital account openness used in empirical analyses, including the empirical analysis presented in Section 3 of this paper. See Edison, Klein Ricci and Sløk (2004) for a discussion of the different indicators of capital account openness used in empirical studies.
} 
where $C$ represents the term in curly brackets in the first line and $S$ represents the term in square brackets in the first line. ${ }^{8}$

Variables included in the term $S$ in [9] include those that represent the determinants of the steady state of an economy that has an open capital account for the proportion $\kappa$ of the period $T$. In particular, $\kappa$, the proportion of time spent with an open capital account, is one of these variables. ${ }^{9}$ A Taylor-series expansion of $S$ around its constituent variables gives us the linear specification

$$
\left[9^{\prime}\right] \frac{1}{T} \ln \left(\frac{y(T)}{y(0)}\right)=-\frac{1}{T} C \ln (y(0))+\gamma \kappa+Z B
$$

where $\mathrm{Z}$ is a row vector of variables other than $\kappa$ that affect $S$, the coefficients on these variables are the elements of the column vector $B$, and both $\gamma$ and the elements of $B$ are obtained from the first-order Taylor series expansion of $S$. In the case of $\gamma$, the expansion around $\kappa=0$ gives us

$$
[10] \gamma=\frac{1}{T} \frac{\partial S}{\partial \kappa}=\lambda e^{\lambda \kappa T}\left[\ln \left(y_{G}^{*}\right)-\left(1-a e^{\lambda(1-\alpha)(1-\kappa) T}\right) \ln \left(y_{A}^{*}\right)\right]
$$

\footnotetext{
${ }^{8}$ The parameter $-(C / T)$ represents the coefficient on the initial income term in a growth regression, and $0<C<1$ (for example, $C=0.32$ when $\alpha=0.3, \beta=0.3, n=0.01, g=0.02$, $\delta=0.05, \kappa=0.5$ and $T=20$ ). As noted above, this model suggests that the rate of conditional convergence is more rapid for countries with more time spent with an open capital account since, with reference to [9], $\frac{d C}{d \kappa}>0$. However, the results presented in Section 3 do not support a significant difference in conditional convergence associated with $\kappa$.

${ }^{9}$ Note that $S=\left(1-e^{-(1-\alpha) \lambda T}\right) \ln \left(y_{A}^{*}\right)$ when $\kappa=0$, and $S=\left(1-e^{-\lambda T}\right) \ln \left(y_{G}^{*}\right)$ when $\kappa=1$.
} 
where $\left(1-a e^{\lambda(1-\alpha)(1-\kappa) T}\right)$ is, for reasonable values of $\alpha, \beta, n, g, \delta$ and $T$, between 0 and $1 .^{10}$ The result in [10] shows that $\gamma$, representing the effect of a given value of $\kappa$ on growth, is bigger when steady state output with open capital markets, $y_{G}^{*}$, is large relative to steady state output with closed capital markets, $y_{A}^{*}$, since $\kappa$ reflects the proportion of time during the period 0 to $T$ with open capital markets. ${ }^{11}$

Institutional quality affects $\gamma$ through its effect on the steady state values of $y_{A}^{*}$ and $y_{G}^{*}$. More precisely, using the result in [10], we have

$$
\text { [11] } \frac{\partial \gamma}{\partial q}=\frac{\alpha \lambda e^{\lambda_{\kappa} T}}{1-\alpha-\beta}\left[\left(-\left\{1-(\alpha+\beta) e^{\lambda(1-\alpha)(1-\kappa) T}\right\}\right) \frac{d \ln x(q)}{d q}-\frac{d \ln \left(r_{W}+\delta+v(q)\right)}{d q}\right] \text {. }
$$

For reasonable parameter values, the term in curly brackets in [11] is positive and, when this is the case, the relationship between $\gamma$ and $q$ may not be monotonic. ${ }^{12}$ Whether $\frac{\partial \gamma}{\partial q}$ is positive or negative depends upon the relative value of $\frac{d \ln x(q)}{d q}$ and $\frac{d \ln \left(r_{W}+\delta+v(q)\right)}{d q}$. In particular, $\frac{\partial \gamma}{\partial q}>0$ if, in absolute value, $\frac{d \ln \left(r_{W}+\delta+v(q)\right)}{d q}$ is large relative to $\frac{d \ln x(q)}{d q}$ since, in this case, the improvement in institutional quality has a relatively big

\footnotetext{
${ }^{10}$ The term $\left(1-a e^{\lambda(1-\alpha)(1-\kappa) T}\right)$ is equal to 0.7 for $\kappa=1$, and to 0.431 for $\kappa=0$, when $T=$ 20 (the number of years in the sample used in the empirical analysis presented below), and the values of $\alpha, \beta, n, g$, and $\delta$ are the same as those listed in footnote 8 .

${ }^{11}$ Note that $\gamma$ can be positive even if $y_{G}^{*}<y_{A}^{*}$ since $\left(1-a e^{\lambda(1-\alpha)(1-\kappa) T}\right)<1$.

${ }^{12}$ In fact, using the parameter discussed above, the term in curly brackets in [11] equals 0.174 for $\kappa=0,0.318$ for $\kappa=1 / 2$, and 0.030 for $\kappa=3 / 4$.
} 
effect on $y_{G}^{*}$ as compared to its effect on $y_{A}^{*}$, while $\frac{\partial \gamma}{\partial q}<0$ when $\frac{d \ln x(q)}{d q}$ is large relative to the absolute value of $\frac{d \ln \left(r_{W}+\delta+v(q)\right)}{d q}$ since, in this case, an improvement in institutional quality has a relatively big effect on $y_{A}^{*}$ as compared to its effect on $y_{G}^{*}$.

Specification of particular functions of $x(q)$ and $v(q)$ enable us to explore further the relationship between $\gamma$ and $q$, and, in particular, to demonstrate that the model can generate an inverted-U shaped relationship consistent with the empirical results presented in the next section. Consider the functions

$$
\begin{aligned}
& x(q)=X^{q-1} \\
& v(q)=e^{-V q}
\end{aligned}
$$

where the logarithm of the parameter $X$ represents the semi-elasticity of the protection of savings against expropriation with respect to the quality of institutions $(X>1)$ and the parameter $V$ represents the semi-elasticity of the real premium paid on foreign funds with respect to institutional quality $(V>0)$. There is an inverted - U shaped relationship between $\gamma$ and $q$ if there is some value of institutional quality $q^{*}$ between 0 and 1 such that, at $q^{*}, \frac{\partial \gamma}{\partial q}=0$ and $\frac{\partial^{2} \gamma}{\partial q^{2}}<0 .{ }^{13}$ For these functions, $q^{*}$ is

$$
\text { [13] } q^{*}=\frac{1}{V} \ln \left[\frac{V-\ln (X) \times\left\{1-(\alpha+\beta) e^{\lambda(1-\alpha)(1-\kappa) T}\right\}}{\left\{1-(\alpha+\beta) e^{\lambda(1-\alpha)(1-\kappa) T}\right\} \times \ln (X) \times\left(r_{W}+\delta\right)}\right] \text {. }
$$

${ }^{13}$ These functional forms meet the requirements outlined above that $x^{\prime}(q)>0, v^{\prime}(q)<0$, $x(1)=1$, and $v(1)$ is small for appropriate values of $V$. Of course, the functions presented here are not the only ones that can generate this inverted-U shaped relationship between $\gamma$ and $q$. A sufficient condition for $q^{*}$ to represent a maximum value is $x^{\prime \prime}\left(q^{*}\right) \leq 0$ and $v^{\prime \prime}\left(q^{*}\right) \times\left(r_{W}+\delta+v\left(q^{*}\right)\right)>\left(v^{\prime}\left(q^{*}\right)\right)^{2}$. 
The central point here is that, for a range of values of $X$ and $V, q^{*}$ is positive and less than 1 . This is demonstrated in Table 1 in which $q^{*}$ is shown to have values between 0.469 and 0.702 when $X$ equals 6,10 , or 14 , and $V$ equals 8,10 or 12 , and the value of the other parameters are those used in earlier discussion. Thus, the largest effect of capital account liberalization on growth occurs among countries with good, but not the best, levels of institutional quality. ${ }^{14}$

\begin{tabular}{|c|c|c|c|c|}
\hline & & $\begin{array}{r}\mathrm{Ta} \\
\text { iated }\end{array}$ & $\begin{array}{l}\text { 1: } \\
\text { Maxi }\end{array}$ & \\
\hline & & $\mathrm{V}=8$ & $\mathrm{~V}=10$ & $\mathrm{~V}=12$ \\
\hline$X=6$ & $Q^{*}$ & 0.702 & 0.585 & 0.503 \\
\hline & $\Gamma$ & 0.0214 & 0.0220 & 0.0225 \\
\hline$X=10$ & $Q^{*}$ & 0.669 & 0.559 & 0.481 \\
\hline & $\Gamma$ & 0.0218 & 0.0226 & 0.0231 \\
\hline$X=14$ & $Q^{*}$ & 0.651 & 0.544 & 0.469 \\
\hline & $\Gamma$ & 0.0221 & 0.0229 & 0.0235 \\
\hline & & $\begin{array}{l}0.3, n= \\
=0.5 \mathrm{~T}=\end{array}$ & $\begin{aligned} g & =0.0 \\
\mathrm{r}_{\mathrm{W}} & =0.0\end{aligned}$ & 0.05 \\
\hline
\end{tabular}

The non-monotonic relationship between $\gamma$ and $q$ is further illustrated by Figures $1 \mathrm{a}$ and $1 \mathrm{~b}$ which trace out $\gamma$ for values of $q$ between 0.3 and 1.0. Figure 1a presents this relationship for three different values of $X(6,10$, and 14), given $V=10$, while Figure $1 \mathrm{~b}$ shows how $\gamma$ varies with $q$ for three different values of $V(8,10$, and 12) when $X=10$ (thus the middle line in each figure, representing $V=10$ and $X=10$, is the same across the two figures). ${ }^{15}$ These figures show that $\gamma$, while consistently positive, first increases, and then decreases, with $q$, reflecting the differential effects of $q$ in the

\footnotetext{
${ }^{14}$ The result in [13] also shows that $q^{*}$ is decreasing in both $X$ and $V$ and that the savings rates, $s_{H}$ and $s_{K}$ do not affect $q^{*}$, although they do affect the maximum value of $\gamma$.

${ }^{15}$ The parameter values used to generate these figures are the same as those used up to this point.
} 
two functions $x(q)$ and $v(q)$. The value of $\gamma$ associated with $q *$ is about 10 percent bigger than its value when evaluated at $q=1$ for the cases of $V=10$ and $X=10$, as well as for the cases where $V=14$ and $X=10$ and $V=10$ and $X=14$. The value of $\gamma$ evaluated at $q^{*}$ is between 20 and 25 percent larger than its value at $q=0.3$ for each of the three cases depicted in Figure 1a, while, for the cases depicted in Figure 1b, the maximum value of $\gamma$, relative to its value at $q=0.3$, ranges from 10 percent larger (for $V=12$ ) to 46 percent larger (for $V=8$ ).

The results presented in Table 1 and Figures $1 \mathrm{a}$ and $1 \mathrm{~b}$ suggest that there may be a non-monotonic relationship between the responsiveness of growth to capital account liberalization and institutional quality. These results are obtained through the use of particular functional forms, but other reasonable specifications of $x(q)$ and $v(q)$ could also generate an inverted-U shaped relationship between $\gamma$ and $q$ (see footnote 13). Different functional forms for $x(q)$ and $v(q)$, however, can produce a monotonic relationship. Ultimately, out interest is in the empirical relationship between $\gamma$ and $q$. We next turn to this question and show that, in fact, the data supports an inverted-U shaped relationship between $\gamma$ and $q$. Furthermore, the estimated values of $\gamma$ presented in Section 3 are similar to those generated in the model developed in this section. 
Figure 1a: Gamma \& q, varying $X(V=10)$

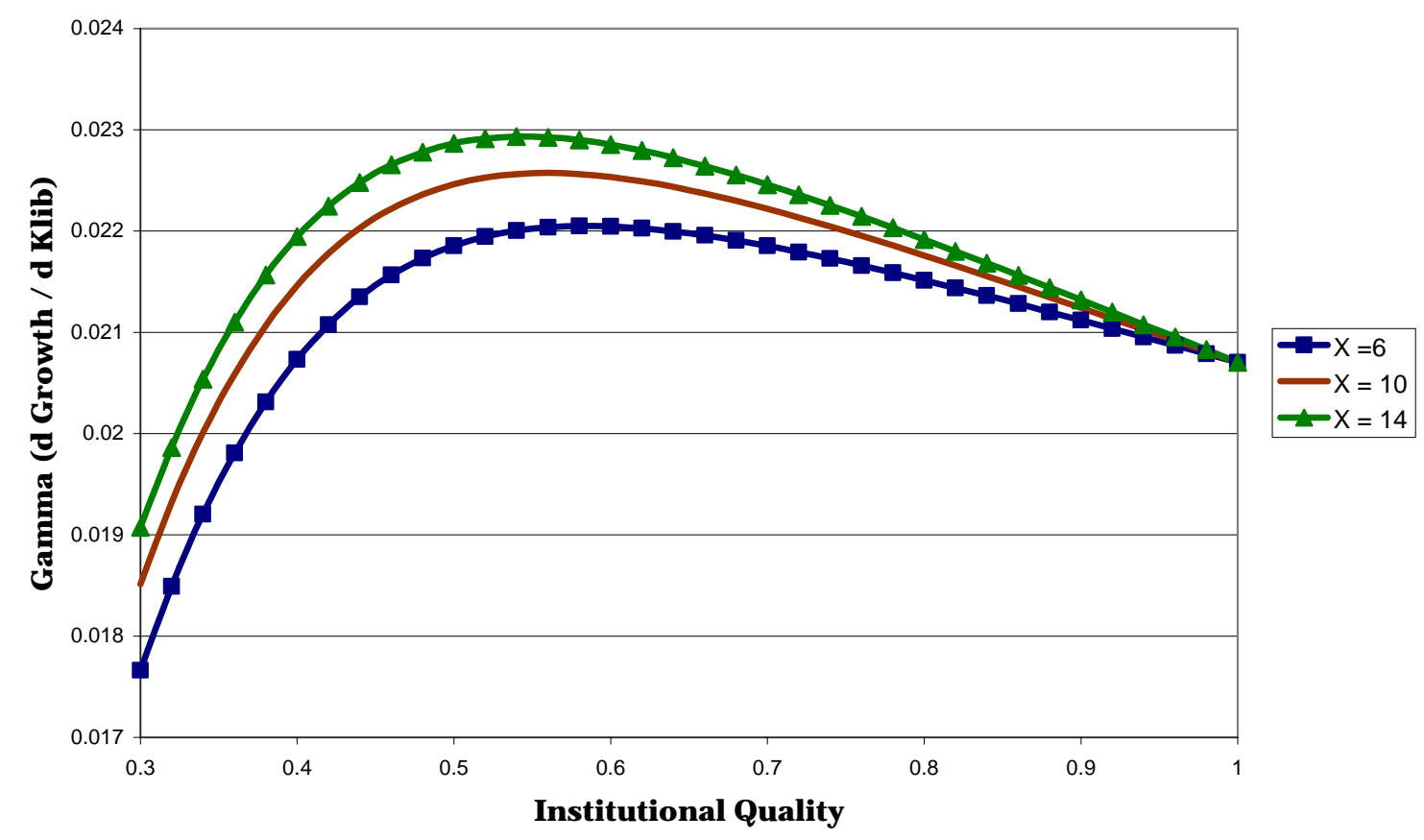

Figure 1b: Gamma \& q, varying V $(X=10)$

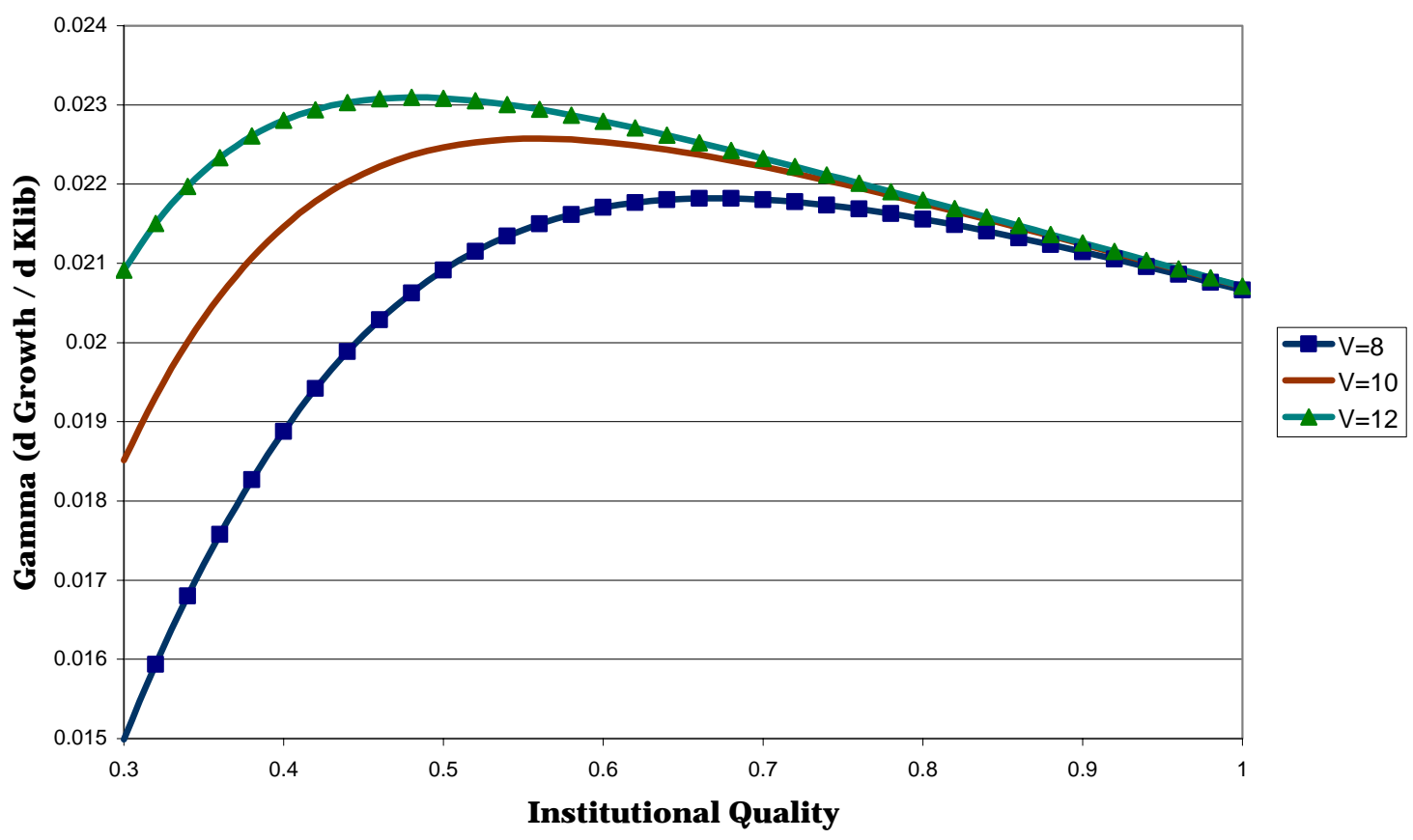




\section{$\underline{\text { 3. Empirical Estimates }}$}

This section presents an empirical analysis of the manner in which the responsiveness of economic growth to capital account openness depends upon an indicator of institutional quality. This analysis considers the performance of 71 countries over the twenty year period 1976 to 1995 . The indicator of capital account openness for country $i, \kappa_{\mathrm{i}}$, is based on the data in the IMF's Annual Report on Exchange Arrangements and Exchange Restrictions, and its value represents the proportion of the years between 1976 and 1995 that this publication reports that country $i$ had an open capital account $(0 \leq$ $\left.\kappa_{\mathrm{i}} \leq 1\right)$. The indicator of institutional quality, $Q_{i}$, represents, for country $i$, the average of five series from the International Country Risk Guide, published by the PRS group, with higher values for each of the five series representing better institutional quality. ${ }^{16}$

We use these data, along with macroeconomic data, to estimate three specifications that, in different ways, allow for a possible non-monotonic interaction between institutional quality and capital account openness. These specifications are presented in Section 3.1. The preferred specification includes interactions between $\kappa$, the capital account openness indicator, and $Q, Q^{2}$ and $Q^{3} \cdot{ }^{17}$ The estimates from this

${ }^{16}$ This empirical indicator of $\kappa_{\mathrm{i}}$ corresponds directly to the definition of $\kappa$ in the model in Section 2. The empirical indicator of institutional quality ranges from 2.45 to 7.22 , with a median value of 4.36. The data appendix provides details on these two indicators.

${ }^{17}$ The inclusion of the cubic term allows for greater flexibility then if the specification only included the interaction terms $\kappa \times Q$ and $\kappa \times Q^{2}$ and, of course, the specification with three interaction terms nests the specification with two interaction terms. These interactions also effectively nest the Edwards (2001) and Arteta, Eichengreen, and Wyplosz (2003) specifications that include a linear interaction between the capital account openness indicator and initial income, since institutional quality is strongly correlated with initial income per capita (see Klein (2003) and the discussion in Edison, Klein, Ricci and Sløk (2004)). Also, by separately including $Q$, the specification presented here nests the one used in Rodrik (1998). 
specification are of an inverted-U shaped relationship between the responsiveness of economic growth to capital account openness and institutional quality. The two other specifications presented in Section 3.1 also yield a similar non-monotonic relationship. Furthermore, the estimated economic importance of open capital markets can be quite pronounced for countries with an appropriate level of institutional quality.

\section{$\underline{3.1 \text { Specifications }}$}

An empirical specification that allows one to test for a non-monotonic relationship between the responsiveness of growth to capital account openness and institutional quality is

$\Delta \ln Y_{76-95, i}=\beta_{1} \ln Y_{76, i}+\beta_{2} Q_{i}+\beta_{3} \kappa_{i}+\beta_{4}\left(\kappa_{i} \times Q_{i}\right)+\beta_{5}\left(\kappa_{i} \times Q_{i}^{2}\right)+\beta_{6}\left(\kappa_{i} \times Q_{i}^{3}\right)+\beta_{7} Z_{i}^{\prime}+\varepsilon_{i}$

where $\Delta \ln Y_{76-95, i}$ is the change in the natural logarithm of real per capital income between 1976 and 1995 of country $i, \ln Y_{76, i}$ is the natural logarithm of real per capita income in 1976 for country $i, \kappa_{i}$ is an indicator of capital account openness of country $i$, and $Q_{i}$ is an indicator of institutional quality for country $i .^{18}$ In this specification, $\gamma$, the responsiveness of the steady state level of output to the indicator of capital account openness, is

\footnotetext{
${ }^{18}$ The matrix $\mathbf{Z}_{\mathbf{i}}$ includes variables that are typical included in cross-country growth regressions (and are included in the model in Section 2), such as the logarithm of the secondary school enrollment rate (a proxy for $E$ ), the average rate of investment to GDP over the years 1974 to 1978 (which, in the steady state, is related to the variables $\mathrm{s}_{\mathrm{H}}$ and $\mathrm{s}_{\mathrm{K}}$ ), and the growth rate of the population between 1976 and 1995 (the parameter $n$ ). As is often the case in empirical investigations of growth, one of the columns of the matrix $\mathbf{Z}_{\mathbf{i}}$ represents a dummy variable for African countries. The model suggests the importance of including the world interest rate as a regressor, but, in a cross-section panel regression, this variable, which is the same for all countries, is subsumed in the constant.
} 


$$
\gamma=\beta_{3}+\left(\beta_{4} \times Q_{i}\right)+\left(\beta_{5} \times Q_{i}^{2}\right)+\left(\beta_{6} \times Q_{i}^{3}\right)
$$

This specification nests a model in which the effect of capital account openness on growth does not depend upon institutional quality (that is, a model in which $\beta_{4}=0, \beta_{5}=$ 0 , and $\beta_{6}=0$ ), a model in which $\gamma$ varies in a linear fashion with institutional quality (in which case $\beta_{5}=0$ and $\beta_{6}=0$ ), and a model in which $\gamma$ varies in a quadratic fashion (a model in which $\beta_{6}=0$ ). A positive value for $\beta_{5}$ and a negative value for $\beta_{6}$ is consistent with an inverted-U shaped relationship between $\gamma$ and $Q_{i}$.

Another hypothesis from the model presented in Section 2 is that the rate of convergence depends upon the proportion of years a country had an open capital account. We test this hypothesis by augmenting specification [14] with a variable that represents the interaction of initial income and capital account openness, as shown in [15] $\Delta \ln Y_{76-95, i}=\beta_{1} \ln Y_{76, i}+\beta_{C}\left(\ln Y_{76, i} \times \kappa_{i}\right)+\beta_{2} Q_{i}+\beta_{3} \kappa_{i}+\beta_{4}\left(\kappa_{i} \times Q_{i}\right)+\beta_{5}\left(\kappa_{i} \times Q_{i}^{2}\right)+\beta_{6}\left(\kappa_{i} \times Q_{i}^{3}\right)+\beta_{7} Z_{i}^{\prime}+\varepsilon_{i}$

The rate of conditional convergence for country $i$ is $\beta_{1}+\left(\beta_{C} \times \kappa_{i}\right)$. The model presented in Section 2 predicts that a longer period with an open capital account contributes to a faster rate of conditional convergence. A test of this hypothesis is whether $\beta_{C}$ is significant and negative. ${ }^{19}$

${ }^{19}$ The partial derivative of growth with respect to capital account openness in [15] is

$$
\gamma=\left(\beta_{C} \times \ln Y_{76, i}\right)+\beta_{3}+\left(\beta_{4} \times Q_{i}\right)+\left(\beta_{5} \times Q_{i}^{2}\right)+\left(\beta_{6} \times Q_{i}^{3}\right)
$$

Initial income is significantly correlated with institutional quality, so we use the estimated values from the regression

$$
\ln Y_{76, i}=\pi_{0}+\pi_{1} Q_{i}+u_{i}
$$

the results of which are reported in Table 3, to calculate the estimated value of $\gamma$ from specification [15] as

$$
\gamma=\left(\beta_{C} \times\left(\hat{\pi}_{0}+\hat{\pi}_{1} Q_{i}\right)\right)+\beta_{3}+\left(\beta_{4} \times Q_{i}\right)+\left(\beta_{5} \times Q_{i}^{2}\right)+\left(\beta_{6} \times Q_{i}^{3}\right)
$$


While the empirical specification [14] is flexible, since it nests a range of possible interactions between $\gamma$ and $Q$, in the interest of robustness the empirical results also include two other specifications that allow for an interaction between capital account openness and institutional quality. One specification replaces the interaction terms in [14] with a quadratic spline,

$\Delta \ln Y_{76-95, i}=\beta_{1} \ln Y_{76, i}+\beta_{2} Q_{i}+\beta_{3} \kappa_{i}+\omega_{1} \kappa_{i}\left(Q_{i}-Q_{M I N}\right)^{2}+\omega_{2} M_{i} \kappa_{i}\left(Q_{i}-\hat{Q}_{K N O T}\right)^{2}+\beta_{7} Z_{i}^{\prime}+\varepsilon_{i}$

where $\hat{Q}_{K N O T}$ is the estimated knot of the spline, $M_{i}$ is a dummy variable that equals 0 for values of $Q_{i} \leq \hat{Q}_{K N O T}$ and otherwise equals 1 , and $Q_{M I N}$ is the minimum value of institutional quality in the sample. In this specification, the responsiveness of growth to capital account liberalization is

$$
\gamma_{\text {SPLINE }}=\beta_{3}+\omega_{1}\left(Q_{i}-Q_{M I N}\right)^{2}+\omega_{2} M_{i}\left(Q_{i}-\hat{Q}_{K N O T}\right)^{2}
$$

Equation [16] is estimated through non-linear techniques that allow for the joint estimation of the $\beta$ and $\omega$ coefficients as well as $\hat{Q}_{K N O T}$ (which determines $M_{i}$ ).

A third specification, one that is even less restrictive in its parameterization, estimates different coefficients for the effect of capital account liberalization on growth for each quintile of institutional quality, as shown by

$$
\text { [17] } \Delta \ln Y_{76-95, i}=\beta_{1} \ln Y_{76, i}+\beta_{2} Q_{i}+\sum_{j=1}^{5} \alpha_{j} D_{j} \kappa_{i}+\beta_{7} Z_{i}^{\prime}+\varepsilon_{i}
$$

where $D_{i}$ represents a dummy variable that equals 1 if country $i$ is in the $j^{\text {th }}$ quintile for institutional quality, and is otherwise equal to zero. The value and pattern of significance of the estimates of the five $\alpha_{j}$ coefficients can be used to confirm the results derived 
from specifications [14] and [16] as to whether, in fact, the effect of capital account openness on economic growth varies systematically with institutional quality.

\subsection{Capital Account Openness, Institutional Quality and Growth}

This section presents estimation results in several ways. The estimated coefficients from regressions along with their standard errors are presented in Table 2. The OLS estimate of [14], the OLS estimate of [15], the IV estimate of [14], the nonlinear least squares estimate of [16], and the estimate of [17] that includes the indicator of capital account openness, $\kappa_{i}$, interacted with the institutional quality quintile dummy variables are reported in Columns $1-5$, respectively.

The results in Columns $1-4$, however, do not provide a transparent answer to the central question of this paper, how the responsiveness of growth to capital account openness varies with institutional quality. Therefore, the lower panel of Table 2 also includes, for Columns $1-4$, estimates of $\gamma$ calculated for the $10^{\text {th }}, 30^{\text {th }}$, median, $70^{\text {th }}$ and $90^{\text {th }}$ percentile values of $Q_{\mathrm{i}}{ }^{20}$ This table also reports the number of countries that have values of $Q_{\mathrm{i}}$ such that the estimated value of $\gamma$ is significant, and the percentiles spanned by this set of countries.

An even more clear representation of the results in Columns $1-5$ is provided in Figures $2-6$, respectively. Each of these figures plots, for one of the specifications reported in Table 2, the estimated value of $\gamma$ (in a line in which filled circles represent

${ }^{20}$ The lower part of Column 5 presents the coefficients on the interaction of $\kappa_{i}$ with the quintile dummy variables, where the percentile listed in the left column represents the midpoint of that quintile (i.e., the row labeled " $10^{\text {th }}$ Percentile" presents the coefficient for $\kappa_{i}$ for the first quintile, the row labeled " $30^{\text {th }}$ Percentile" presents the coefficient for $\kappa_{i}$ for the second quintile, and so on). 
estimates of $\gamma_{i}$ for actual values of $Q_{\mathrm{i}}$ ), along with the associated 95 percent confidence intervals (dashed lines). Figures 3, 4, 5, and 6 also include plots of $\gamma$ as estimated in Column 1 (as diamonds unconnected by a line) for purposes of comparing results across specifications and estimation methods. Figures $2-5$ also include a vertical line drawn at the smallest value of $Q_{\mathrm{i}}$ at which $\gamma$ is significant at the 95 percent level of confidence, and another vertical line drawn at the largest value of $Q_{\mathrm{i}}$ at which $\gamma$ is significant at the 95 percent level of confidence.

The OLS estimate of Specification [14], reported in Column 1 of Table 2, and represented in Figure 2, shows that capital account openness is a significant determinant of growth over the period 1976 to 1995 for a set of countries with above-median levels of institutional quality. The coefficient on $\kappa_{i}$ itself, as well as the coefficient on each of the three interaction terms, $\kappa_{i} \times Q_{i}, \kappa_{i} \times Q_{i}{ }^{2}$, and $\kappa_{i} \times Q_{i}{ }^{3}$, are significant at better than the 95 percent level of confidence. This suggests that a cubic interaction between $\kappa_{i}$ and $Q_{i}$, as opposed to no interaction, a linear interaction, or a quadratic interaction, is warranted. The lower panel of Table 2 shows that, with this specification and estimation method, 17 of the 71 countries in the sample ( 23.9 percent of the countries) have a value of $\gamma$ that is significant. The set of countries represents those with institutional quality ranging from the $55^{\text {th }}$ percentile (Mexico) to the $79^{\text {th }}$ percentile (Ireland).

The quantitative effect of having an open capital account is economically meaningful, as well as statistically significant, for countries with institutional quality between that of Mexico and Ireland. For example, consider two hypothetical countries that are similar along all relevant dimensions, including initial income and their institutional quality. The strongest support for the opening sentence of this paragraph can 


\begin{tabular}{|c|c|c|c|c|c|c|}
\hline \multicolumn{7}{|c|}{ Table 2: Growth, Capital Account Liberalization, \& Institutional Quality } \\
\hline \multirow[b]{2}{*}{$\ln Y_{1976, i}$} & \multirow{2}{*}{$\begin{array}{c}1: \text { OLS } \\
-0.396 \\
\end{array}$} & \multirow{2}{*}{\begin{tabular}{|c|}
$2:$ OLS \\
-0.374 \\
\end{tabular}} & \multirow{2}{*}{$\begin{array}{c}3: \text { IV } \\
-0.295\end{array}$} & \multicolumn{2}{|c|}{ 4: Non-linear LS Spline } & \multirow{2}{*}{\begin{tabular}{|l|}
$5:$ OLS \\
-0.380 \\
\end{tabular}} \\
\hline & & & & & -0.371 & \\
\hline (s.e.) & $(0.136)$ & $(0.158)$ & $(0.138)$ & & $(0.100)$ & $(0.137)$ \\
\hline $\ln Y_{76} \times \kappa_{i}$ & & -0.217 & & & & \\
\hline (s.e.) & & $(0.376)$ & & & & \\
\hline$Q_{, i}$ & 0.439 & 0.424 & 0.439 & & 0.415 & 0.438 \\
\hline (s.e.) & $(0.097)$ & $(0.114)$ & $(0.187)$ & & $(0.077)$ & $(0.096)$ \\
\hline $\boldsymbol{\kappa}_{i}$ & 12.325 & 14.967 & 15.905 & & 0.181 & \multirow{8}{*}{$\begin{array}{c}\text { Coef.on } \\
\text { (Share } \\
\times \\
\text { Quintile } \\
\text { Dummy) } \\
\text { given } \\
\text { below }\end{array}$} \\
\hline (s.e.) & $(5.925)$ & $(6.455)$ & $(24.166)$ & & $(0.430)$ & \\
\hline$\left(\kappa_{i} \times Q_{, i}\right)$ & -8.388 & -9.317 & -12.049 & $\omega_{1}$ & 0.046 & \\
\hline (s.e.) & $(3.863)$ & $(3.796)$ & $(15.393)$ & (s.e.) & $(0.069)$ & \\
\hline$\left(\kappa_{i} \times Q_{, i}{ }^{2}\right)$ & 1.861 & 2.065 & 2.848 & $\omega_{2}$ & -0.477 & \\
\hline (s.e.) & $(0.806)$ & $(0.799)$ & $(3.122)$ & (s.e.) & $(0.360)$ & \\
\hline$\left(\kappa_{i} \times Q_{i}{ }^{3}\right)$ & -0.131 & -0.143 & -0.210 & Knot & 5.218 & \\
\hline (s.e.) & $(0.054)$ & $(0.053)$ & $(0.205)$ & (s.e.) & $(1.205)$ & \\
\hline Ln(School) & 0.058 & 0.053 & -0.074 & & 0.033 & 0.030 \\
\hline (s.e.) & $(0.093)$ & $(0.095)$ & $(0.178)$ & & $(0.106)$ & $(0.093)$ \\
\hline Invest $_{A v}{ }^{\prime} 74-78$ & 0.016 & 0.015 & 0.023 & & 0.018 & 0.015 \\
\hline (s.e.) & $(0.008)$ & $(0.008)$ & $(0.019)$ & & $(0.008)$ & $(0.009)$ \\
\hline Pop.Growth & -0.712 & -0.712 & -0.967 & & -0.773 & -0.557 \\
\hline (s.e.) & $(0.410)$ & $(0.414)$ & $(0.781)$ & & $(0.389)$ & $(0.404)$ \\
\hline Africa & -0.628 & -0.632 & -0.599 & & -0.638 & -0.701 \\
\hline (s.e.) & $(0.157)$ & $(0.159)$ & $(0.231)$ & & $(0.172)$ & $(0.151)$ \\
\hline Percentiles & \multicolumn{5}{|c|}{ Overall Effect, $\gamma_{i}$, for $i$ at listed percentiles of $Q_{i}$} & $\boldsymbol{\alpha}_{\mathbf{i}}$ \\
\hline $10^{\text {th }}$ Percentile & 0.417 & 0.057 & -0.342 & & & 0.526 \\
\hline (s.e.) & $(0.358)$ & $(0.379)$ & $(0.720)$ & & & $(0.408)$ \\
\hline $30^{\text {th }}$ Percentile & 0.123 & 0.148 & -0.097 & & & -1.322 \\
\hline (s.e.) & $(0.243)$ & $(0.244)$ & $(0.731)$ & & & $(0.999)$ \\
\hline $50^{\text {th }}$ Percentile & 0.249 & 0.251 & 0.367 & & & -0.257 \\
\hline (s.e.) & $(0.203)$ & $(0.206)$ & $(0.599)$ & & & $(0.331)$ \\
\hline $70^{\text {th }}$ Percentile & 0.664 & 0.684 & 0.613 & & & 0.572 \\
\hline (s.e.) & $(0.186)$ & $(0.187)$ & $(0.286)$ & & & $(0.278)$ \\
\hline $90^{\text {th }}$ Percentile & -0.151 & -0.126 & -1.384 & & & -0.147 \\
\hline (s.e.) & $(0.236)$ & $(0.239)$ & $(1.183)$ & & & $(0.221)$ \\
\hline $\begin{array}{c}\# \text { w/sig. }+ \text { effect } \\
\text { percentiles }\end{array}$ & $\begin{array}{c}17 \\
55^{\text {th }}-79^{\text {th }}\end{array}$ & $\begin{array}{c}17 \\
55^{\text {th }}-79^{\text {th }}\end{array}$ & $63^{\text {rd }}-72^{\text {nd }}$ & $62^{1}$ & & $\begin{array}{c}14^{*} \\
60^{\text {th }}-80^{\text {th }}\end{array}$ \\
\hline $\mathrm{R}^{2}$ & 0.732 & 0.745 & 0.61 & & & 0.73 \\
\hline No. of obs. & 71 & 71 & 59 & & & 71 \\
\hline \multicolumn{7}{|c|}{$\begin{array}{c}\text { Bold }=\text { significant }>95 \% \text { level of confidence, } \text { Italic }=\text { sig. at } 90 \% \text { to } 95 \% \text { level of conf. } \\
\text { Column 4: } \omega_{1} \text { is coef. on } \boldsymbol{\kappa}_{\boldsymbol{i}}\left(\mathbf{Q}-\mathbf{Q}_{\boldsymbol{M I N}}\right)^{\mathbf{2}}, \omega_{2} \text { is coef. on } \boldsymbol{M} \times \boldsymbol{\kappa}_{\boldsymbol{i}}\left(\mathbf{Q}-\mathbf{Q}_{\boldsymbol{K}}\right)^{\mathbf{2}} \\
\text { Column 5: } \alpha_{\mathrm{i}} \text { represents estimate at for midpoint of } i^{\text {th }} \text { quintile } \\
* \text { by construction, }(\text { number } / \text { quintile }) \times(\text { number of sig. quintile coefficients })\end{array}$} \\
\hline
\end{tabular}


be made by assuming that $Q$ equals 5.75 for both of these economies (the level of institutional quality for Korea) since $\gamma$ reaches a maximum value of 0.67 at this level of $Q$. If one of these countries maintained capital controls throughout the sample period while the other kept an open capital account, the estimated annual average growth rate of the open economy would be 3.35 percentage points greater than that of the closed economy, and the open economy would be 95 percent bigger than the closed economy after two decades. Of course, this is the maximum difference that is obtained with these estimates. But differences are notable with other assumed values of $\kappa_{i}$ and $Q_{i}$ as well. For example, at $Q=4.64$, a level of institutional quality just below that of Mexico, the point of the lower 95 percent confidence bound in the estimate with constant convergence, the estimated value of $\gamma$ is 0.357 . This suggests a difference of 1.79 percentage points in annual growth between a fully closed and a fully open economy, and a difference of 43 percent in per capita income after two decades. Even comparing two economies for which $Q=4.64$, with one that is closed and one that is open only during the second half of the sample, there is a difference of 0.893 percentage points in the annual growth rate, a difference that would result in a difference of 20 percent between the continually closed and periodically open economy after two decades. ${ }^{21}$

While these results strongly support one prediction of the model presented in Section 2, another prediction, that an open economy experiences more rapid conditional convergence than a closed economy, is not consistent with the empirical results. Column

\footnotetext{
${ }^{21}$ These values of $\gamma$ are broadly consistent with those presented in the theoretical model since the estimates of $\gamma$ in the theoretical model represent effects on average annual growth and, consequently, the values of $\gamma$ from the theoretical model must be multiplied by 20 to be compared them to the estimates of $\gamma$ presented here. For example, the value of 20 times the maximum values of $\gamma$ presented in Table 2 ranges from 0.428 to 0.47 .
} 
2 presents the estimates from Specification [15] that allows for the possibility of varying conditional convergence through the inclusion of the interaction between initial income and the indicator of capital account openness. As predicted by the theory, the estimated value of this interaction term is negative, but it is not significant (the p-value is 0.57 ). ${ }^{22}$

The estimated $\gamma$ obtained with varying conditional convergence is almost identical to the $\gamma$ obtained under the assumption of constant conditional convergence. ${ }^{23}$ In Figure 3 , the estimates of $\gamma$ for varying conditional convergence (represented by the line with the filled circles on it) and under the assumption of constant conditional convergence (represented by the unconnected diamonds) track each other very closely. In fact, as shown in the lower panels of Columns 1 and 2 in Table 2, the set of countries with a significant value of $\gamma$ for the varying conditional convergence estimate is the same as that for the constant conditional convergence estimate. Therefore, because of the lack of support for varying conditional convergence, and the similarity of results concerning how $\gamma$ varies with $Q$ across these two specifications, all further results presented here consider only the case of constant conditional convergence.

Column 3 of Table 2 presents instrumental variable estimates of Specification [14], and Figures 4 plots the associated estimate of $\gamma$, along with its 95 percent confidence interval. The instruments used in these estimates include $\kappa_{i}$ for the period 1970 to 1974 , similarly constructed indicators of current account openness, a multiple exchange rate regime, and surrender of export proceeds, the average of trade divided by

\footnotetext{
${ }^{22}$ Sachs and Warner (1995) argue that unconditional convergence is more rapid in open economies, although their definition of openness differs from the one used here.

${ }^{23}$ The estimates from a specification with a varying rate of convergence employ the results of the regression of $Q_{\mathrm{i}}$ on $\ln Y_{76, i}$ reported in Panel B of Table A.2 (cf. fn. 19).
} 

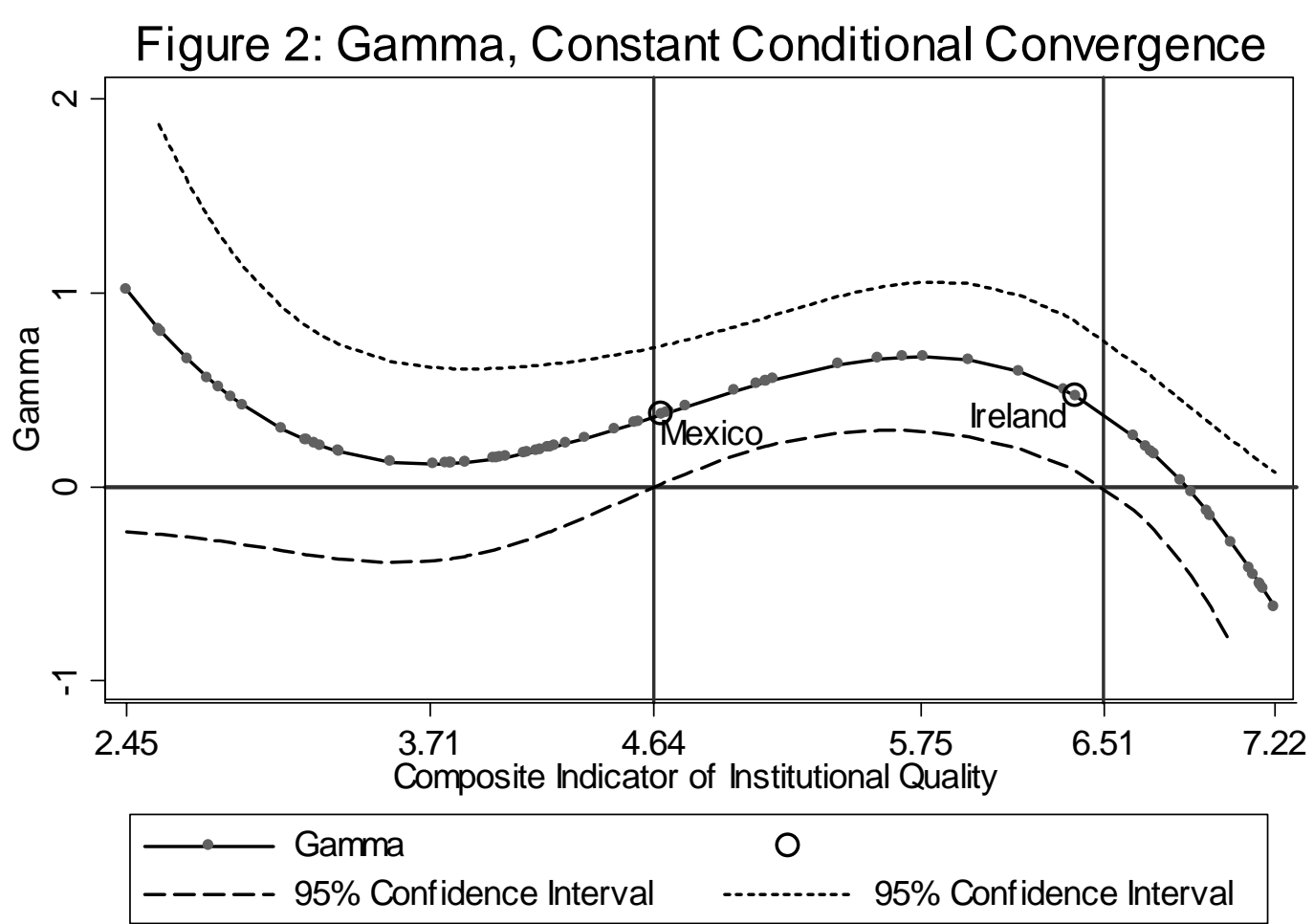

Figure 3: Gamma, Varying Conditional Convergence

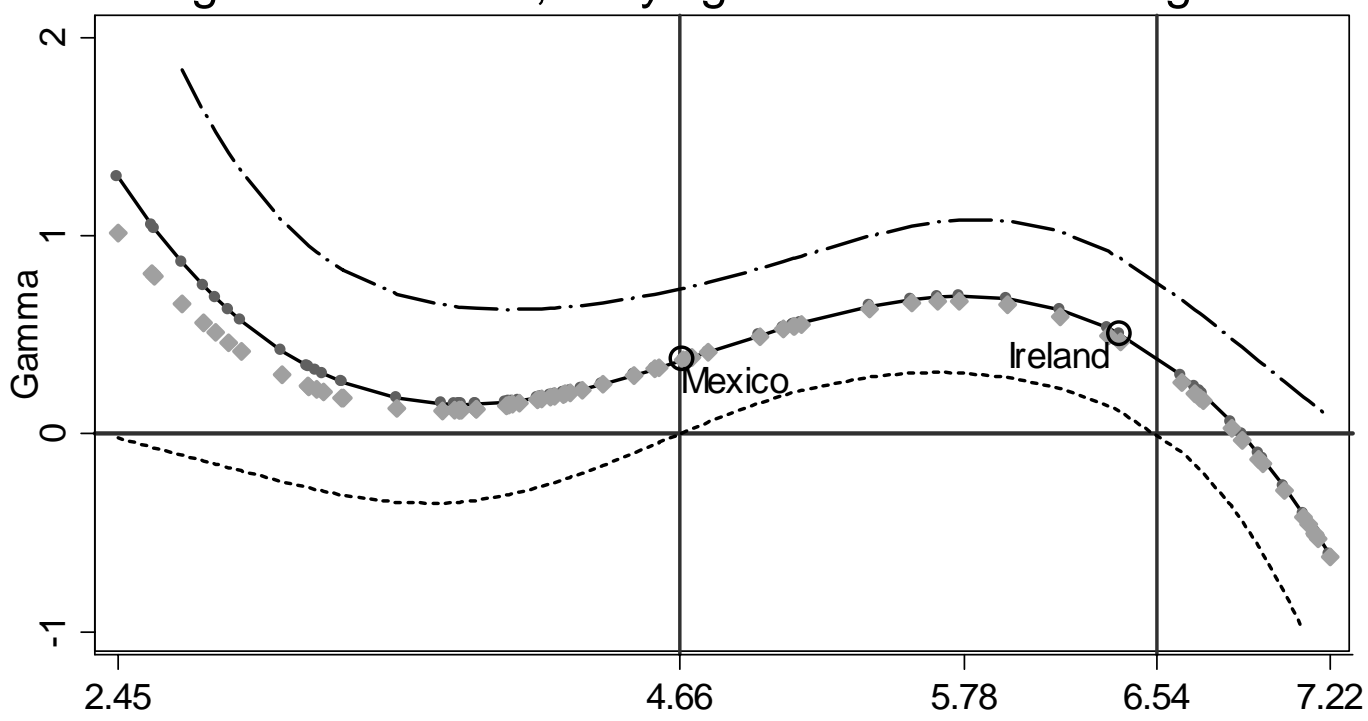

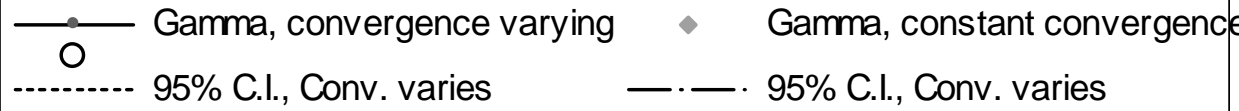


GDP over the period 1970 to 1974, Quinn's (1997) indicator of the intensity of capital account controls in 1973 and his indicator of the intensity of current account controls for that year, and a set of regional dummy variables. These instruments are used for $\kappa_{i}$ as well as the for interactions of $\kappa_{i}$ with institutional quality. ${ }^{24}$

The lower panel of Columns 3 shows that fewer countries have a significant estimated value of $\gamma$ with IV estimates than with OLS estimates, a result partially due to the smaller sample available for the IV estimates, but also one typically found when comparing IV to OLS estimates. Figure 4 also shows, however, that over the range of values of $Q_{i}$ for which $\gamma$ is significant in the IV estimates, or even over the larger range of values of $Q_{i}$ for which $\gamma$ is significant in the OLS estimates, the IV and OLS estimates of $\gamma$ track each other closely.

The fourth column of Table 2 presents the estimates of Specification [16] which includes a quadratic spline, with the knot of the spline estimated simultaneously with the coefficients of the regression using nonlinear least squares. The lower panel of this column shows that 9 countries, those with institutional quality between the $62^{\text {nd }}$ and $73^{\text {rd }}$ percentiles, have significant estimated effects of capital account openness on growth. The size of the estimated effect for the $70^{\text {th }}$ percentile is only about 16 percent different than the effect for the country at that same percentile using Specification [14].

The similarity between the estimated effects of institutional quality on the responsiveness of economic growth to capital account openness in the spline and cubic interaction specifications is shown more fully in Figure 5. The plot of $\gamma$ estimated with a quadratic spline specification (the line with the filled circles) as well as the plot of $\gamma$ from

\footnotetext{
${ }^{24}$ The $\mathrm{R}^{2}$ in the first-stage regression for $\kappa_{i}$ is 0.64 .
} 
Figure 4: Gamma, IV Estimate

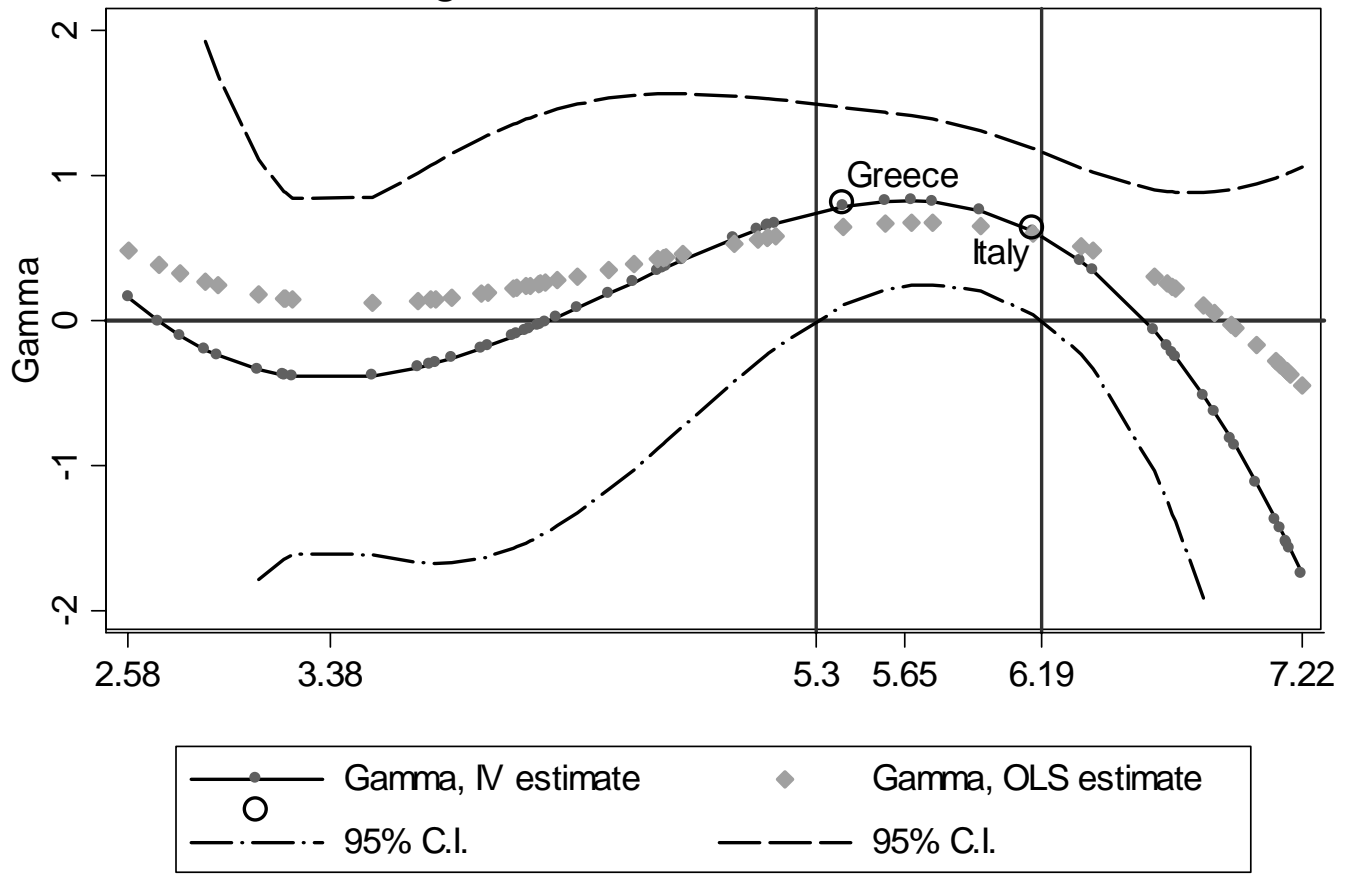

Figure 5: Gamma, Quadratic Spline

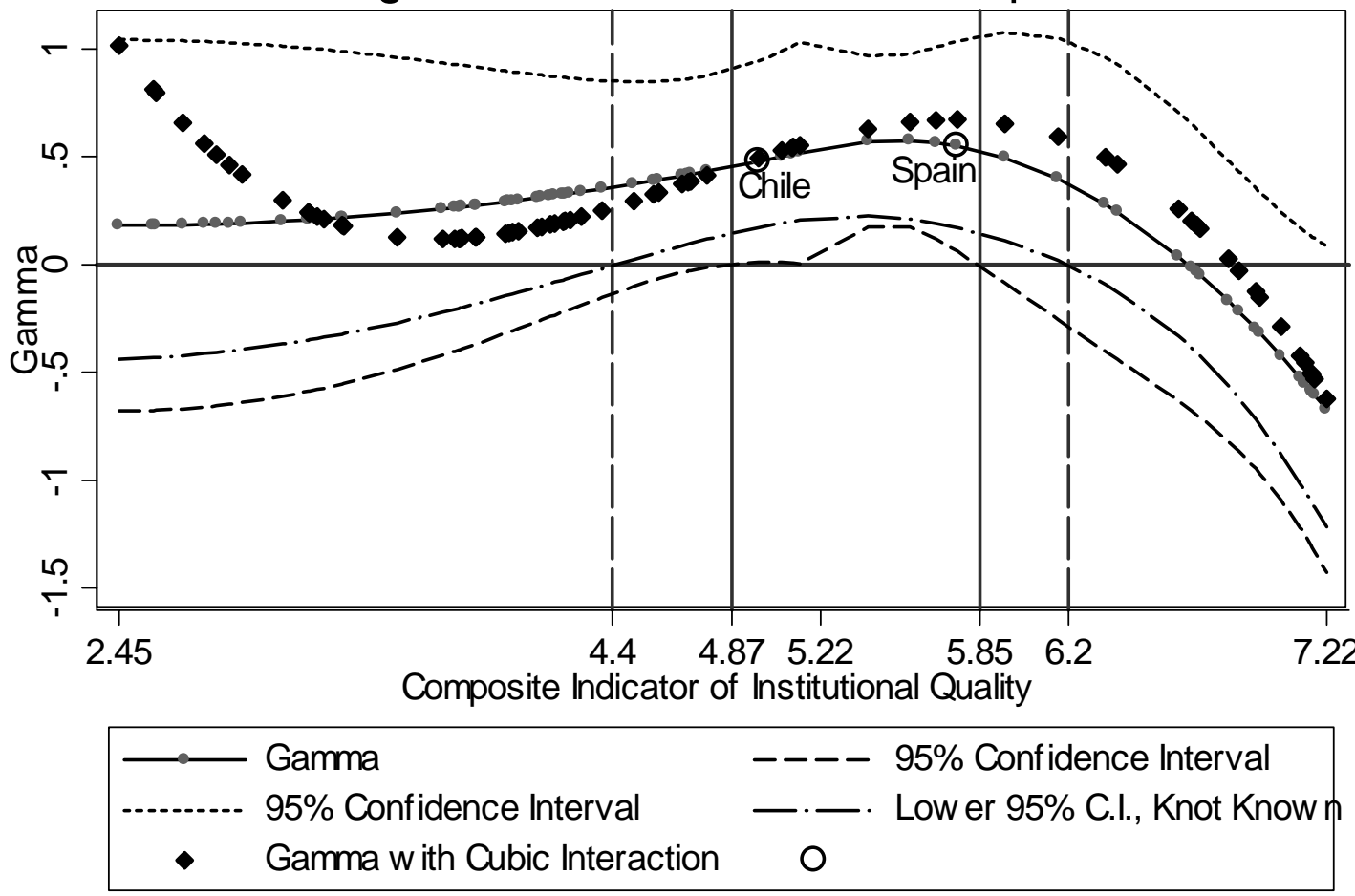


the basic cubic interaction (the unconnected diamonds) track each other closely. Figure 5 also includes the upper and lower 95 percent confidence intervals for $\gamma$, as well as the lower 95 percent confidence interval for $\gamma$ if the estimated value of the knot, 5.218, is treated as a known parameter rather than an estimate. This latter confidence interval gives a much wider range of significant values of $\gamma$ (even though the p-value for the estimate of the knot is less than 0.001), as shown by the dashed vertical lines, with 23 of the 71 countries having estimates of $\gamma$ that are significant at better than the 95 percent level of confidence when the value of the knot is treated as a parameter of the model.

The final column in Table 2 presents the estimates of Specification [17] in which $\kappa_{i}$ is interacted with a set of dummy variables representing the quintiles of institutional quality. The results in this column show that the coefficient on $\kappa_{i}$ is only significant for the $4^{\text {th }}$ quintile, that is, from the $60^{\text {th }}$ percentile to the $80^{\text {th }}$ percentile. This corresponds closely to the more parameterized results presented in Columns 1 and 2, where significant values of $\gamma$ are obtained for countries between the $55^{\text {th }}$ and $79^{\text {th }}$ percentiles. Also, the estimated value of $\gamma$ of 0.572 for the $4^{\text {th }}$ quintile is within the range of significant values of $\gamma$ from the estimates in Columns 1 and 2 of 0.357 to 0.670 .

The close correspondence between the estimates of $\gamma$ from Specification [14] and Specification [17] is also demonstrated by Figure 6 . This figure shows that the $4^{\text {th }}$ quintile, for which institutional quality ranges form 4.81 to 6.67 , is the only one in which the confidence interval for $\gamma$ does not overlap zero. In this range, the estimated values of $\gamma$ from Specification [14], represented by the unconnected diamonds, closely correspond to the estimate from Specification [17]. Thus, the overall result for the effect of 
institutional quality on the responsiveness of growth to capital account openness is robust to results from this different estimation technique.

Figure 6: Gamma, By Quintiles

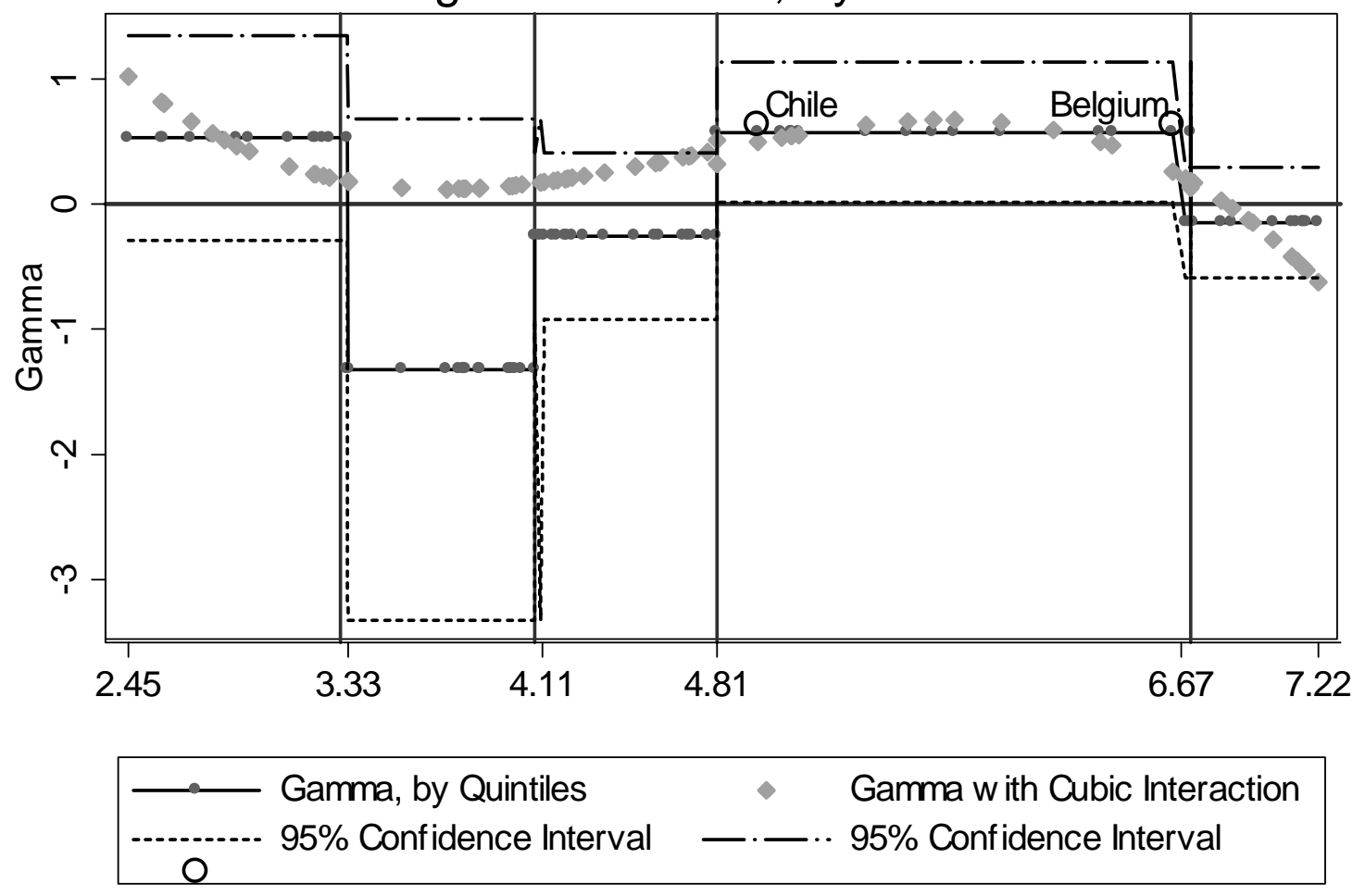




\section{$\underline{\text { 4. Conclusion }}$}

The debate over the consequences of capital account liberalization tends to be painted in broad strokes of black and white. This paper suggests a more nuanced approach, one that allows for shades of gray.

The model in this paper presents a logical framework demonstrating that the effect of capital account liberalization on economic growth varies with institutional quality. Estimates from several empirical specifications consistent with this model suggest that an open capital account can make a statistically significant and economically meaningful contribution to economic growth. But, as predicted by the theory presented earlier in the paper, this estimated effect varies with institutional quality. In particular, the effect of capital account openness on growth is found to be statistically significant for about one-quarter of the countries in the sample, and these countries tend to be ones with better (though not the best) institutions. There is a strong correlation between institutional quality and income per capita, and the countries that tend to benefit significantly from capital account liberalization are mostly upper-middle-income countries.

At a policy level, the results presented in this paper answer, to some extent, the critics of capital account liberalization who assert that its benefits have not been demonstrated. But the model and empirical results presented here do not offer an unqualified endorsement of capital account liberalization either. Instead, the main message of this paper is that the environment in which this policy takes place can have an important effect on its consequences. 


\section{$\underline{\text { Data Appendix }}$}

\section{Indicators of Capital Account Openness and Institutional Quality}

In this data appendix we discuss the indicators of capital account openness and institutional quality used in the regressions.

\section{A.1 Indicator of Capital Account Openness}

The theoretical model presented in Section 2 includes the parameter $\kappa$ that represents the proportion of years that a country had a continuously open capital account. For the empirical analysis in this paper, we construct the indicator of capital account openness $\kappa_{i}$ that represents the proportion of years between 1976 and 1995 that country $i$ is recorded a country as having an open capital account by the Annual Report on Exchange Arrangements and Exchange Restrictions (AREAER), a publication of the International Monetary Fund. ${ }^{25}$ This indicator has been used in other empirical studies of the effects of capital account openness on growth, including Grilli and Milesi-Ferretti (1995), Rodrik (1998) and Klein and Olivei (1999). ${ }^{26}$

\footnotetext{
${ }^{25}$ Every issue of the Annual Report on Exchange Arrangements and Exchange Restrictions published between 1967 (which refers to conditions in 1966) and 1996 (which refers to conditions in 1995) includes a summary table in which row E.2, labeled "Restrictions on payments for capital transactions," addresses the presence or absence of capital controls. The 1997 issue of Annual Report on Exchange Arrangements and Exchange Restrictions expanded the summary information on capital controls including, for the first time, a distinction between restrictions on inflows and restrictions on outflows. Unfortunately, this new classification system cannot be mapped into the early system, making the use of a panel bridging the pre-1996 and post-1996 data problematic.

${ }^{26}$ An alternative empirical indicator of capital account openness developed by Dennis Quinn (1997) attempts to record the intensity of controls. Quinn's indicators are only available for a limited set of years for non-industrial countries. Edison, Klein, Sløk and Ricci (2004) compare $\kappa_{i}$ to Quinn's indicators
} 
Table A.1 presents some statistics and information on $\kappa_{i}$. The IMF publication records that about half of the countries in the data set (36 of the 71 countries for which we have full data) had closed capital accounts throughout this period. Among the 35 countries that had some experience with open capital accounts (a set that includes all 17 industrial countries in the sample), 6 were recorded as having had open capital accounts each year from 1976 to 1995; the United States, Belgium, the Netherlands, Canada, Malaysia and Hong Kong.

As defined here, $\kappa_{i}$ does not distinguish between a one-time liberalization and an on-again, off-again pattern of capital account restrictions. Fortunately, in the large majority of observations in the data set, $\kappa_{i}$ corresponds directly to $\kappa$ in the theoretical model, that is, it reflects an early period with capital account restrictions and, if nonzero, a later period with an open capital account. For the 29 countries where $\kappa_{i}$ did not equal 0 or 1 , the governments of 20 of them (all 14 industrial countries and 6 of the 15 nonindustrial countries that had a value of $\kappa_{i}$ greater than 0 but less than 1) did not close the capital accounts once it was opened. ${ }^{27}$

\begin{tabular}{|c|c|c|c|}
\hline \multicolumn{4}{|c|}{ Table A.1: Capital Account Openness Indicator } \\
\hline \multicolumn{4}{|c|}{$\begin{array}{c}\kappa_{i}=\text { proportion of years with open capital accounts } \\
\text { (from IMF Exchange Arrangements and Exchange Restrictions) } \\
71 \text { observations, } 36=0,35 \neq 0 .\end{array}$} \\
\hline \multicolumn{4}{|c|}{$\begin{array}{l}\text { Percentiles (for non-zero cases) } \\
\end{array}$} \\
\hline $25^{\text {th }}$ & $50^{\text {th }}$ & $75^{\text {th }}$ & $90^{\text {th }}$ \\
\hline 0.15 & 0.35 & 0.85 & 1.00 \\
\hline
\end{tabular}

${ }^{27}$ For details on this, see Edison, Klein, Ricci and Sløk (2004). 


\section{A.2 Indicator of Institutional Quality}

A variety of indicators of institutional quality have been used in empirical research. The composite indicator used in this paper, $Q_{\mathrm{i}}$, represents, for country $i$, the 1984 to 1995 average of five series from the data set constructed by Steve Knack and Philip Keefer of the IRIS Center at the University of Maryland; Bureaucratic Quality, Control of Corruption in Government, Risk of Expropriation, Repudiation of Government Contracts, and Rule of Law (Law and Order Tradition). These series are based on data from the International Country Risk Guide, published by the PRS Group. ${ }^{28}$ A higher value for any of the indicators represents a higher quality of an institution so, for example, a higher score for Repudiation of Government Contracts means less of a risk of repudiation and a higher score for Risk of Expropriation means a smaller risk.

Table A.2 presents some statistics for $Q_{i}$. Panel A shows the minimum and maximum values, as well as the values for the $10^{\text {th }}, 30^{\text {th }}, 50^{\text {th }}, 70^{\text {th }}$ and $90^{\text {th }}$ percentiles, for the 71 observations in the sample. The regression of the logarithm of income per capita in 1976 on $Q_{i}$, presented in Panel B, shows a highly significant link between the logarithm of initial income per capita and institutional quality. ${ }^{29}$ The results in Panel C show that there is a very high correlation between all five components of the overall indicator of institutional quality. This high correlation explains why the results of the estimates presented below are largely unchanged if any single component is used rather than the average of all five, as well as if a different weighting scheme is used to calculate the overall indicator of institutional quality.

${ }^{28}$ See http://www.prsgroup.com/icrg/icrg.html.

${ }^{29}$ As mentioned in footnote 15, this estimate is used to evaluate $\gamma$ in specification [15]. 


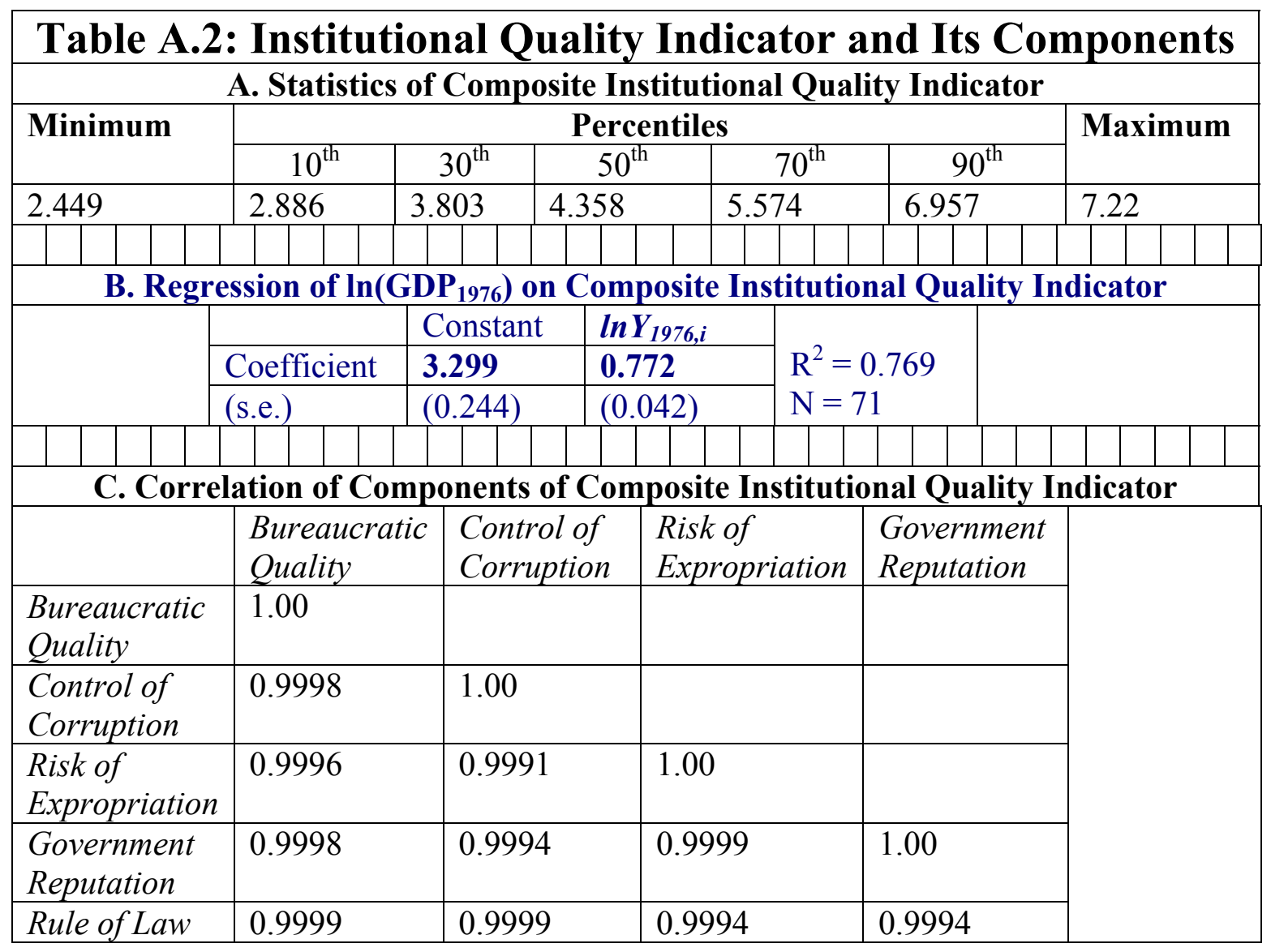




\section{References}

Alfaro, Laura, Sebnem Kalemli-Ozcan and Vadym Volosovych, 2003, "Why Doesn't Capital Flow from Rich to Poor Countries?" mimeo.

,2005, "Capital Flows in a Globalized World: The Role of Policies and Institutions," NBER Working Paper no. 11696, October.

Arteta, Carlos, Barry Eichengreen and Charles Wyplosz, 2003, "When Does Capital Account Liberalization Help More Than It Hurts?" in Elhanan Helpman and Efraim Sadka, eds., Economic Policy in the International Economy, Cambridge University Press, pp. 177 - 206.

Barro, Robert, N. Gregory Mankiw and Xavier Sala-i-Martin, 1995, "Capital Mobility in Neoclassical Models of Growth," American Economic Review, vol 85, no. 1, (March), pp. $103-115$.

Bhagwati, Jagdish, 1998, "The Capital Myth: The Difference Between Trade in Widgets and Trade in Dollars," Foreign Affairs, Vol. 77, pp. 7-12.

Edison, Hali, Michael W. Klein, Luca Ricci and Torsten Sløk, 2004, "Capital Account Liberalization and Economic Growth: Survey and Synthesis," International Monetary Fund Staff Papers, vol. 51, no. 2, pp. 22 - 256, August.

Edwards, Sebastian, "Capital Mobility and Economic Performance: Are Emerging Markets Different?" in Horst Siebert, ed., The World's New Financial Landscape: Challenges for Policy, Springer Publishers, c. 2001, pp. 219 - 244.

Froot, K. A., and Jeremy Stein. 1991, "Exchange Rates and Foreign Direct Investment: An Imperfect Capital Markets Approach," Quarterly Journal of Economics, vol. 106 (November), pp. 1191-1217.

Grilli, Vittorio, and Gian Maria Milesi-Ferretti, 1995, "Economic Effects and Structural Determinants of Capital Controls," IMF Staff Papers, Vol. 42, No. 3, pp. 517-51.

International Monetary Fund, 2000, Report of the Managing Director to the International Monetary and Financial Committee on Progress in Strengthening the Architecture of the International Financial System and Reform of the IMF, September 19.

Klein, Michael W., "Capital Account Openness and the Varieties of Growth Experience," NBER Working Paper no. 9500, February 2003.

, and Giovanni Olivei, 1999, "Capital Account Liberalization, Financial Depth and Economic Growth,” N.B.E.R. Working Paper no. 7384, October. 
Mankiw, N. Gregory, David Romer and David N. Weil, 1992, "A Contribution to the Empirics of Economic Growth," Quarterly Journal of Economics, vol. 107, no.1 2, (May), pp. $407-437$.

Quinn, Dennis, 1997, “The Correlates of Change in International Financial Regulation," American Political Science Review, Vol. 91, No. 3, (September), pp. 531-51.

Rodrik, Dani, 1998, "Who Needs Capital-Account Convertibility?” in Stanley Fischer, et al., Should the IMF Pursue Capital Account Convertibility? Essays in International Finance, No. 207, International Finance Section, Department of Economics, Princeton University, Princeton, N.J., (May).

,1999, The New Global Economy and Developing Countries: Making Openness Work, Overseas Development Council, Policy Essay no. 24, Washington, D.C., distributed by the Johns Hopkins University Press, Baltimore, Maryland.

Rogoff, Kenneth S., 2002, "Rethinking Capital Controls: When should we keep an open mind?," Finance and Development, December, pp. 55 - 56.

Sachs, Jeffrey D., and Andrew Warner, 1995, "Economic Reform and the Process of Global Integration," Brookings Papers on Economic Activity, vol. 1, pp. 1 - 95. 